\title{
LA ACCESIBILIDAD WEB. UN RETO EN EL ENTORNO EDUCATIVO ECUATORIANO.
}

\author{
Milton Campoverde Molina
}

Recibido: octubre de 2016 Aprobado: diciembre de 2016 


\title{
LA ACCESIBILIDAD WEB. UN RETO EN EL ENTORNO EDUCATIVO ECUATORIANO
}

\section{WEB ACCESSIBILITY. A CHALLENGE IN THE ECUADORIAN EDUCATIONAL ENVIRONMENT}

\author{
Milton Alfredo Campoverde Molina \\ Unidad Académica de Tecnologías de la Información y la Comunicación, \\ Universidad Católica de Cuenca (UCACUE) \\ Cuenca-Ecuador \\ mcampoverde@ucacue.edu.ec
}

\begin{abstract}
Resumen
Es un estudio retro prospectivo que revela la evaluación de accesibilidad de los portales web de 31 Unidades Educativas y colegios de la ciudad de Cuenca - Ecuador, aplicando las Pautas de Accesibilidad para el Contenido Web (WCAG) 2.0 con un nivel de conformidad; para el análisis se aplicó la herramienta automática TAW Online y la evaluación se hace sobre las tecnologías HTML y CSS, utilizando las WCAG 2.0, dando como resultado que los portales web no cumplen con las directrices de Accesibilidad Web definidas en la WCAG 2.0 con un nivel de conformidad A y sus errores se deben a que las páginas web no son lo suficientemente robustas para ser interpretadas de forma fiable por una amplia variedad de agentes de usuario, incluyendo las ayudas técnicas; además, se debe proporcionar alternativas textuales en todo el contenido no textual, información y relaciones, secuencia con el significado, características sensoriales, uso del color, contraste, redimensionamiento del texto e imágenes de texto.
\end{abstract}

Palabras clave: Accesibilidad Web, Colegios, Discapacidad, Unidades Educativas, WCAG 2.0.

\begin{abstract}
It is a prospective retro study revealing assessment of accessibility of web portals 31 Education and Schools Units Cuenca - Ecuador applying Accessibility Guidelines Web Content (WCAG) 2.0 with a level of conformity A, for analysis automatic tool TAW Online was applied and the evaluation is done on HTML and CSS technologies using WCAG 2.0, resulting in the web portals do not meet the guidelines web Accessibility defined in WCAG 2.0 with a level of conformity a and errors are because web pages are not robust enough to be interpreted reliably by a wide variety of user agents, including assistive technologies also should provide text alternatives for all non-text content, information and relations, Sequence with meaning, sensory characteristics, use of color, contrast, resizing text and images of text.
\end{abstract}

Keywords: Web accessibility, Schools, Disabilities, Educational Units, WCAG 2.0.

Recibido: octubre de 2016

Aprobado: diciembre de 2016 


\section{Introducción}

Según la OMS en su informe mundial sobre la discapacidad 2011 estima que más de mil millones de personas viven con algún tipo de discapacidad; o sea, alrededor del $15 \%$ de la población mundial (según las estimaciones de la población mundial en 2010). Esta cifra es superior a las estimaciones previas de la Organización Mundial de la Salud, correspondientes a los años 1970, que eran de aproximadamente un10\% [1].

Según la Encuesta Mundial de Salud, cerca de 785 millones de personas $(15,6 \%)$ de 15 años y más viven con una discapacidad, mientras que el proyecto sobre la Carga Mundial de Morbilidad estima una cifra próxima a los 975millones (19,4 \%). La Encuesta Mundial de Salud señala que, del total estimado de personas con discapacidad, 110 millones $(2,2 \%)$ tienen dificultades muy significativas de funcionamiento, mientras que la Carga Mundial de Morbilidad cifra en 190 millones $(3,8 \%)$ las personas con una "discapacidad grave"(el equivalente a la discapacidad asociada a afecciones tales como la tetraplejía, depresión grave o ceguera). Solo la Carga Mundial de Morbilidad mide las discapacidades infantiles (0-14 años), con una estimación de 95 millones de niños (5,1 $\%), 13$ millones de los cuales $(0,7 \%)$ tienen "discapacidad grave"[1].

En base al registro nacional de discapacidades del ministerio de salud pública del Ecuador, emitido el 2 de febrero 2016[2] establece que en el Ecuador existen 408.021 personas con discapacidad y en las estadísticas del registro nacional de discapacidades de abril 2015 [3] se determina que existen 28.968 personas con discapacidad en la provincia del Azuay y 19.127 en la ciudad de Cuenca.

De acuerdo a las estadísticas presentadas en abril del 2015, se determina que el 66\% de personas con discapacidades de la provincia del Azuay se encuentra en la ciudad de Cuenca: auditiva (7\%), física (36\%), intelectual $(12 \%)$, lenguaje(1\%), psicológica (1\%), psicosocial $(1 \%)$, visual $(8 \%)$ y en las estadísticas presentadas en febrero de 2016 se evidencia que el $1 \%$ de personas con discapacidades se encuentran incluidas en la educación popular permanente, el 55\% en educación regular y el $44 \%$ en educación especial en el Sistema Nacional de Educación.

Esto demuestra que el $55 \%$ de personas con discapacidad se encuentran cursando sus estudios en educación regular. De ahí, la importancia de evaluar los portales web de las unidades educativas y colegios de la ciudad de Cuenca para determinar el nivel de conformidad de la accesibilidad de los mismos.

Anthony Lake, Director Ejecutivo, UNICEF expone ¿Existe algún niño que no sueñe con que le tengan en cuenta, o que no aspire a que se reconozcan sus cualidades? No. Todos los niños y las niñas tienen esperanzas y sueños, incluso aquellos con discapacidad. Y todos merecen una oportunidad para hacer realidad sus sueños [4].El CONADIS [5] en las normas jurídicas en discapacidad Ecuador establece el "Acceso a una educación inclusiva y especializada de calidad a las personas con discapacidad que atienda sus necesidades específicas" (educación), así como el "Acceso al medio físico, Servicios de transporte, Tecnologías de la información y comunicación", las mismas que están enmarcadas en el Plan Nacional para el Buen Vivir 2013- 2017[6] y en su segundo objetivo que es promover la igualdad, inclusión y equidad social; además en el Art. 65 de la Ley Orgánica de Discapacidades se expresa la "Atención prioritaria en portales web", las instituciones públicas y privadas que prestan servicios públicos, incluirán en sus portales web, un enlace de acceso para las personas con discapacidad, de manera que accedan a información y atención especializada y prioritaria, en los términos que establezca el reglamento.

Las personas con discapacidad, históricamente han tenido que hacer frente a obstáculos de toda índole para acceder a espacios y procesos sociales e interaccionar y participar en la sociedad, como sujetos activos en igualdad de condiciones, encuentran en las tecnologías y sus aplicaciones un nuevo medio capaz de superar muchas de estas barreras ${ }^{\mathrm{i}}$, ofreciendo una puerta de acceso y participación real y efectiva [7].

El impacto de la discapacidad se cambia radicalmente en la web porque la Web elimina barreras a la comunicación y la interacción que muchas personas se enfrentan en el mundo físico. Sin embargo, cuando los sitios web, las tecnologías web, o herramientas de la web están mal diseñados, pueden crear barreras que excluyen a las personas el uso de la Web[8]. Es decir, no sólo a los discapacitados permanentes, sino también aquellas personas cuyas capacidades se vean reducidas por un tiempo determinado, ya sea por una enfermedad, un accidente, etc. [9].

\section{Objetivo:}

El objetivo de esta investigación es determinar el nivel de accesibilidad de los portales web de los unidades educativas y colegios ${ }^{\text {ii }}$ de la ciudad de Cuenca, a través del análisis de cumplimiento de las Pautas de Accesibilidad para el Contenido Web (WCAG) 2.0 con un Nivel de Conformidad A; ya que el Ecuador al igual que otros países a través del 
Registro Oficial No. 171 del 28 de enero de 2014, cuenta ya con la norma NTE INEN-ISO/IEC 40500 Tecnología de la información - Directrices de accesibilidad para el contenidoweb ${ }^{\text {iii }}$ del W3C (WCAG) 2.0 (ISO/IEC 40500:2012, IDT) [11]; la adopción de esta norma, emite una amplia gama de recomendaciones para eliminar barreras de accesibilidad web para adultos mayores, ciudadanas y ciudadanos con discapacidad, como la ceguera, sordera, problemas de aprendizaje, limitaciones cognitivas, movimiento limitado, problemas del habla, fotosensibilidad y combinaciones de éstos, con la aplicación de estas recomendaciones los portales web permitirán interactuar a los usuarios con mayor facilidad con la información disponible en sus sitios web [12].

\section{Marco Teórico 2.1 Accesibilidad WEB}

Según Tim Berners-Lee, inventor de la World Wide Web, el poder de la web está en su universalidad. El acceso por cualquier persona, independientemente de la discapacidad que presente es un aspecto esencial [10].

Hablar de Accesibilidad Web es hablar de un acceso universal a la web, independientemente del tipo de hardware, software, infraestructura de red, idioma, cultura, localización geográfica y capacidades de los usuarios. La idea principal radica en hacer la Web más accesible para todos los usuarios independientemente de las circunstancias y los dispositivos involucrados a la hora de acceder a la información. Partiendo de esta idea, una página accesible lo sería tanto para una persona con discapacidad, como para cualquier otra persona que se encuentre bajo circunstancias externas que dificulten su acceso a la información (en caso de ruidos externos, en situaciones donde nuestra atención visual y auditiva no está disponible, pantallas con visibilidad reducida, etc.)[13].

Según Shawn Lawton Henry, la accesibilidad Web significa que personas con algún tipo de discapacidad van a poder hacer uso de la Web. Hablar de accesibilidad Web se está haciendo referencia a un diseño Web que va a permitir que estas personas puedan percibir, entender, navegar e interactuar con la Web, aportando a su vez contenidos [14], beneficiando a personas con una incapacidad transitoria y a personas de edad avanzada que han visto reducidas sus habilidades a consecuencia de la edad [15].

Asimismo, existe una serie de mitos sobre la accesibilidad web que perduran desde hace años. Estos mitos se pueden resumir en que la accesibilidad web es cara y supone un coste extra en el desarrollo de un sitio $w_{e b} b^{\text {iv }}$, sin que los beneficios sean importantes, otro de los mitos es creer que la accesibilidad web sólo beneficia a las personas con discapacidad [16].

En definitiva, un sitio web es accesible cuando puede ser utilizado de forma eficaz por el mayor número posible de personas, independientemente de sus limitaciones personales[17].

\subsection{Pautas de Accesibilidad para el contenido Web (WCAG) 2.0}

Las (WCAG) 2.0 se compone de 4 principios, 12 directrices y 61 criterios de cumplimiento (éxito), más un número no determinado de técnicas suficientes y técnicas de asesoramiento [18]:

1) Principio 1: Perceptible: la información y los componentes de la interfaz de usuario deben ser mostrados alos usuarios en formas que ellos puedan entender.

- Directriz 1.1: Texto alternativo: Proporciona texto alternativo para el contenido que no sea textual, así podrá ser transformado en otros formatos que la gente necesite, como caracteres grandes, lenguaje braille(braile no es correcto), lenguaje oral, símbolos $\mathrm{o}$ lenguaje más simple.

- Directriz 1.2: Contenido multimedia dependiente del tiempo: Proporcione alternativas sincronizadas para contenidos multimedia sincronizados dependientes del tiempo.

- Directriz 1.3: Adaptable: Crear contenido que pueda ser presentado de diferentes formas sin perder ni información ni estructura.

- Directriz 1.4: Distinguible: Facilitar a los usuarios ver y escuchar el contenido incluyendo la distinción entre lo más y menos importante.

Este principio tiene 22 criterios de cumplimiento.

2) Principio 2: Operable: Los componentes de la interfaz de usuario y la navegación debe ser manejable.

- Directriz 2.1: Teclado accesible: Poder controlar todas las funciones desde el teclado.

- Directriz 2.2 Tiempo suficiente: Proporciona tiempo suficiente a los usuarios para leer y utilizar el contenido.

- Directriz 2.3: Ataques epilépticos: No diseñar contenido que pueda causar ataques 
epilépticos.

- Directriz 2.4: Navegación: Proporciona formas para ayudar a los usuarios a navegar, a buscar contenido y a determinar dónde están estos.

Este principio tiene 20 criterios de cumplimiento.

3) Principio 3: Comprensible: La información y las operaciones de usuarios deben ser comprensibles.

- Directriz 3.1: Legible. Hacer contenido de texto legible y comprensible.

- Directriz 3.2 Previsible: Hacer la apariencia y la forma de utilizar las páginas web previsibles.

- Directriz 3.3 Asistencia a la entrada de datos: los usuarios de ayuda evitarán y corregirán errores.

Este principio tiene 17 criterios de cumplimiento.

4) Principio 4: Robustez: el contenido deber ser suficientemente robusto para que pueda ser bien interpretado por una gran variedad de agentes de usuario, incluyendo tecnologías de asistencia.

- Directriz 4.1 Compatible: Maximiza la compatibilidad con los agentes de usuario actuales y futuros, incluyendo tecnologías de asistencia.

Este principio tiene 2 criterios de cumplimiento.

Según la WCAG 2.0, para que una página web sea conforme con las WCAG 2.0, deben satisfacerse todos los requisitos de conformidad siguientes [19]:

1) Nivel de conformidad: Uno de los siguientes niveles de conformidad se satisface por completo.

- Nivel A: Para lograr conformidad con el Nivel A (el mínimo), la página web satisface todos los Criterios de Conformidad del Nivel A, o proporciona una versión alternativa conforme.

- Nivel AA: Para lograr conformidad con el Nivel AA, la página web satisface todos los Criterios de Conformidad de los Niveles A y AA, o proporciona una versión alternativa conforme al Nivel AA.

- Nivel AAA: Para lograr conformidad con el Nivel AAA, la página web satisface todos los Criterios de Conformidad de los Niveles A, AA y AAA, o proporciona una versión alternativa conforme al Nivel AAA.

2) Páginas completas: La conformidad (y los niveles de conformidad) se aplican a las páginas web completas, y no pueden ser alcanzadas si se excluye una parte de la página.

3) Procesos completos: Cuando una página web es parte de una serie de páginas web que presentan un proceso (es decir, una secuencia de pasos que es necesario completar para realizar una actividad), todas las páginas en ese proceso deben ser conformes con el nivel especificado o uno superior. (No es posible lograr conformidad con un nivel en particular si una de las páginas del proceso no cumple con ese nivel o uno superior).

4) Uso exclusivo de tecnologías de modo compatible con la accesibilidad: Sólo se puede depender de las tecnologías usadas de forma compatible con la accesibilidad para satisfacer los criterios de conformidad. Toda información o funcionalidad que se proporcione de una forma que no sea compatible con la accesibilidad debe estar disponible de una forma que sí sea compatible con la accesibilidad.

5) Sin interferencia: Si las tecnologías se usan de una forma que no es compatible con la accesibilidad, o están usadas de una forma que no cumple los requisitos de conformidad, no deben impedir a los usuarios acceder al contenido del resto de la página. Además, es necesario que la página web en su conjunto siga cumpliendo con los requisitos de conformidad en las siguientes circunstancias:

- Cuando cualquier tecnología de la que no se depende está activada en una aplicación de usuario,

- Cuando cualquier tecnología de la que no se depende está desactivada en una aplicación de usuario, y

- Cuando cualquier tecnología de la que no se depende no es soportada por una aplicación de usuario.

Además, los siguientes criterios de conformidad se aplican a todo el contenido de la página, incluyendo el contenido del que, de todos modos, no se depende para alcanzar la conformidad, ya que su incumplimiento puede interferir con el uso de la página:

1.4.2 - Control del audio,

2.1.2 - Sin trampas para el foco del teclado,

2.3.1 - Umbral de tres destellos o menos, y

2.2.2 - Poner en pausa, detener, ocultar.

Cuando una página cumple con las Pautas WCAG 2.0puede incluir en ella una Declaración que indique a los usuarios que cumple con el W3C [20].

El nivel de conformidad alcanzado se representa mediante un logotipo como se puede ver en la Figura 
1.

\begin{tabular}{|c|c|c|}
\hline $\begin{array}{c}\text { Nivel de } \\
\text { Conformidad } \\
\text { A. }\end{array}$ & $\begin{array}{c}\text { Nivel de } \\
\text { Conformidad } \\
\text { AA. }\end{array}$ & $\begin{array}{c}\text { Nivel de } \\
\text { Conformidad } \\
\text { AAA. }\end{array}$ \\
\hline N3C WAAI-A & WBC WA & WBC WAI- \\
\hline
\end{tabular}

Figura 1. Logos que representan los niveles de accesibilidad alcanzados.

\subsection{Herramienta para el análisis de la accesibilidad de sitios web}

Las herramientas automáticas de evaluación de la accesibilidad web son programas de software o servicios en línea, que realizan una inspección automática para ayudar a determinar si un portal web satisface las guías de accesibilidad web [21].

TAW es una herramienta para evaluar la accesibilidad de páginas web Online con las WCAG 2.0; el mismo que tiene como objetivo "comprobar el nivel de accesibilidad alcanzado en el diseño y desarrollo de páginas web con el fin de permitir el acceso a todas las personas independientemente de sus características diferenciadoras" [22].

Esta herramienta evalúa una página web mediante su dirección URL, con un nivel de conformidad A, AA o AAA sobre las tecnologías HTML, CSS, JAVASCRIPT; la evaluación se realiza en base a las Pautas de Accesibilidad al Contenido Web 2.0 y genera un informe HTML que muestra el total de los problemas encontrados (son necesarias las correcciones), las advertencias (deben revisarse manualmente) y los puntos no verificados (que requieren un análisis manual completo) y los organiza por cada principio: Perceptible, Operable, Comprensible y Robusto.

\section{Materiales y Métodos}

Esta investigación inicia con el planteamiento de la siguiente interrogante ¿Cuántas unidades educativas y colegios existen en la ciudad de Cuenca? para responder a esta pregunta se solicitó el listado de las unidades educativas y colegios a los dos distritos del ministerio de educación de la ciudad de Cuenca, con la información suministrada se determina que en la ciudad de Cuenca existen 560 establecimientos educativos entre Unidades Educativas y Colegios, como se puede observar en la Tabla 1.

\begin{tabular}{|c|c|}
\hline Distritos & Unidades Educativas y Colegios \\
\hline Distrito 01D01 & 245 \\
\hline Distrito 01D02 & 315 \\
\hline Total & $\mathbf{5 6 0}$ \\
\hline
\end{tabular}

Tabla 1: Distritos del ministerio de educación de la ciudad de Cuenca.

Fuente: Distritos del ministerio de educación de la ciudad de Cuenca
Desglosados se observa en las Tablas 2 y 3:

\begin{tabular}{|l|c|}
\hline \multicolumn{2}{|c|}{ Distrito 01D01 } \\
\hline \multicolumn{1}{|c|}{ Tipo } & Unidades Educativas y Colegios \\
\hline Fiscales & 135 \\
\hline Fiscomisionales & 11 \\
\hline Municipales & 5 \\
\hline Particulares & 94 \\
\hline \multicolumn{1}{|c|}{ Total } & $\mathbf{2 4 5}$ \\
\hline
\end{tabular}

Tabla 2: Tipos de Unidades Educativas y Colegios Distrito 01D01 del ministerio de educación de la ciudad de Cuenca. Fuente: Distritos del ministerio de educación de la ciudad de Cuenca

\begin{tabular}{|l|c|}
\hline \multicolumn{2}{|c|}{ Distrito 01D02 } \\
\hline Tipo & Unidades Educativas y Colegios \\
\hline Fiscales & 222 \\
\hline Fiscomisionales & 15 \\
\hline Municipales & 2 \\
\hline Particulares & 76 \\
\hline \multicolumn{1}{|c|}{ Total } & $\mathbf{3 1 5}$ \\
\hline
\end{tabular}

Tabla 3: Tipos de Unidades Educativas y Colegios Distrito 01D02 del ministerio de educación de la ciudad de Cuenca. Fuente: Distritos del ministerio de educación de la ciudad de Cuenca

Considerando que la Constitución Ecuatoriana garantiza los derechos humanos sin discriminación alguna, para lo cual el Art. 347 establece que: "Será responsabilidad del Estado: Numeral 8. Incorporar las tecnologías de la información y comunicación en el proceso educativo y propiciar el enlace de la enseñanza con las actividades productivas o sociales" [23], esto ha motivado a las instituciones educativas a informatizar sus servicios y procesos para que estén al alcance de los estudiantes y puedan acceder a sus contenidos a través de la web.

Según los dominios del Ecuador [24] los nombres de dominio.edu.ec son "Solo para Entidades, Instituciones u Organizaciones Educativas tales como Colegios, Universidades, Escuelas e Institutos registrados en Ecuador"; tomando en cuenta este parámetro se seleccionó como muestra a 31 portales web de forma aleatoria como se observa en la Tabla 4.

\begin{tabular}{|l|l|l|}
\hline $\begin{array}{c}\text { Abreviatur } \\
\text { as }\end{array}$ & $\begin{array}{c}\text { Unidades Educativas } \\
\text { y Colegios }\end{array}$ & $\begin{array}{c}\text { URL Portal Web } \\
\text { (.edu.ec) }\end{array}$ \\
\hline $\begin{array}{l}\text { uesmacuenc } \\
\text { a }\end{array}$ & $\begin{array}{l}\text { Unidad Educativa } \\
\text { Salesiana María } \\
\text { Auxiliadora }\end{array}$ & $\begin{array}{l}\text { www.uesmacuenca } \\
\text {.edu.ec }\end{array}$ \\
\hline ueoblatas & Corazón de María & $\begin{array}{l}\text { www.ueoblatas.ed } \\
\text { u.ec }\end{array}$ \\
\hline sscc & SagradoCorazón & $\begin{array}{l}\text { www.sscc- } \\
\text { cuenca.edu.ec }\end{array}$ \\
\hline $\begin{array}{l}\text { sudamerican } \\
\text { o }\end{array}$ & Sudamericano & $\begin{array}{l}\text { www.sudamerican } \\
\text { o.edu.ec }\end{array}$ \\
\hline
\end{tabular}




\begin{tabular}{|c|c|c|}
\hline ueda & $\begin{array}{l}\text { Unidad Fiscomisional a } \\
\text { Distancia del Azuay }\end{array}$ & www.ueda.edu.ec \\
\hline amauta & AMAUTA & $\begin{array}{l}\text { www.amauta.edu.e } \\
\mathrm{c}\end{array}$ \\
\hline $\begin{array}{l}\text { arzobisposer } \\
\text { rano }\end{array}$ & Arzobispo Serrano & $\begin{array}{l}\text { www.arzobisposerr } \\
\text { ano.ucacue.edu.ec }\end{array}$ \\
\hline continental & Continental & $\begin{array}{l}\text { www.continental.e } \\
\text { du.ec }\end{array}$ \\
\hline adistanciabg & Bill Gates & $\begin{array}{l}\text { www.colegioadista } \\
\text { nciabg.edu.ec }\end{array}$ \\
\hline manueljcalle & Manuel J Calle & $\begin{array}{l}\text { www.colegiomanu } \\
\text { eljcalle.edu.ec }\end{array}$ \\
\hline herlindatoral & HerlindaToral & $\begin{array}{l}\text { www.colegioherlin } \\
\text { datoral.edu.ec }\end{array}$ \\
\hline $\begin{array}{l}\text { americancoll } \\
\text { ege }\end{array}$ & American College & $\begin{array}{l}\text { www.americancoll } \\
\text { ege.edu.ec }\end{array}$ \\
\hline mariorizzini & Mario Rizzini & $\begin{array}{l}\text { www.mariorizzini. } \\
\text { edu.ec }\end{array}$ \\
\hline comilcue & AbdónCalderón & $\begin{array}{l}\text { www.comilcue.edu } \\
\text {.ec }\end{array}$ \\
\hline verbo & $\begin{array}{l}\text { UnidadEducativa } \\
\text { Cristiana Verbo }\end{array}$ & www.verbo.edu.ec \\
\hline casc & $\begin{array}{l}\text { AlemánStiehle de } \\
\text { Cuenca }\end{array}$ & www.casc.edu.ec \\
\hline aaschool & Asian American School & $\begin{array}{l}\text { www.aaschool.edu. } \\
\text { ec }\end{array}$ \\
\hline catalinas & $\begin{array}{l}\text { Unidad Educativa } \\
\text { Particular Rosa de } \\
\text { Jesús Cordero }\end{array}$ & $\begin{array}{l}\text { www.catalinas.edu. } \\
\text { ec }\end{array}$ \\
\hline uemo & $\begin{array}{l}\text { Unidad Educativa } \\
\text { Misioneros Oblatos }\end{array}$ & www.uemo.edu.ec/ \\
\hline $\begin{array}{l}\text { delasallecue } \\
\text { nca }\end{array}$ & $\begin{array}{l}\text { Unidad Educativa } \\
\text { Particular Hermano } \\
\text { Miguel de la Salle } \\
\end{array}$ & $\begin{array}{l}\text { www.delasallecuen } \\
\text { ca.edu.ec }\end{array}$ \\
\hline laasuncion & La Asunción & $\begin{array}{l}\text { www.laasuncion.e } \\
\text { du.ec }\end{array}$ \\
\hline santana & $\begin{array}{l}\text { UnidadEducativa } \\
\text { Santana UNESA }\end{array}$ & $\begin{array}{l}\text { www.santana.edu.e } \\
\mathrm{c} /\end{array}$ \\
\hline madrid & Madrid & $\begin{array}{l}\text { www.unidadeducat } \\
\text { ivamadrid.edu.ec }\end{array}$ \\
\hline uebi & BilingüeInteramericano & http://uebi.edu.ec/ \\
\hline benignomalo & BenignoMalo & $\begin{array}{l}\text { www.colegiobenig } \\
\text { nomalo.edu.ec }\end{array}$ \\
\hline uelac & $\begin{array}{l}\text { Liceo Americano } \\
\text { Católico }\end{array}$ & www.uelac.edu.ec \\
\hline ueporvenir & Porvenir & $\begin{array}{l}\text { www.ueporvenir.e } \\
\text { du.ec }\end{array}$ \\
\hline uets & TécnicoSalesiano & www.uets.edu.ec \\
\hline unidadborja & Borja & $\begin{array}{l}\text { www.unidadborja. } \\
\text { edu.ec }\end{array}$ \\
\hline $\begin{array}{l}\text { sindicatocho } \\
\text { feres }\end{array}$ & $\begin{array}{l}\text { Colegio Particular } \\
\text { Sindicato de Choferes } \\
\text { de la Ciudad de Cuenca }\end{array}$ & $\begin{array}{l}\text { www.sindicatodec } \\
\text { hoferes.edu.ec/ }\end{array}$ \\
\hline $\begin{array}{l}\text { latinoameric } \\
\text { ano }\end{array}$ & $\begin{array}{l}\text { Centro Educativo } \\
\text { Latinoamericano }\end{array}$ & $\begin{array}{l}\text { www.latinoamerica } \\
\text { no.edu.ec }\end{array}$ \\
\hline
\end{tabular}

Las páginas web analizadas en cada uno de los portales web se detallan en la Tabla 5.

\begin{tabular}{|c|c|c|}
\hline Frecuencia & $\begin{array}{c}\text { Páginas } \\
\text { Analizadas }\end{array}$ & $\begin{array}{c}\text { Total de Páginas } \\
\text { Evaluadas }\end{array}$ \\
\hline 1 & 3 & 3 \\
\hline 3 & 4 & 12 \\
\hline 4 & 5 & 20 \\
\hline 5 & 6 & 30 \\
\hline 18 & 7 & 126 \\
\hline 31 & 25 & 191 \\
\hline
\end{tabular}

Tabla 5. Páginas Analizadas de los Portales web de las Unidades Educativas y Colegios.

La evaluación se realizó a 191 páginas web a las que el estudiante accede con mayor frecuencia para informarse o realizar alguna actividad académica (Home, requisitos de matrícula, proceso de admisión, becas, noticias, calendario de eventos, galería, aulas virtuales, webmail, sistema académico, etc.).

Las páginas como Webmail, Aulas Virtuales y Sistemas Académicos (Notas) solo se realizaron el análisis del login por no contar con las contraseñas para el ingreso y evaluación de sus contenidos.

\subsection{Análisis WCAG 2.0 en Todas las Páginas.}

El Reglamento técnico ecuatoriano RTE INEN 288 "accesibilidad para el contenido web" establece en el numeral 4. REQUISITOS: inciso $4.1 \mathrm{El}$ sitio web y los contenidos publicados, debe cumplir con los principios, pautas y criterios de conformidad establecidos en la Norma NTE INEN-ISO/IEC 40500, vigente y en el inciso 4.2 Los criterios de conformidad que deben utilizarse para evaluar la conformidad del contenido Web ya existente o para desarrollar nuevos contenidos Web de forma accesible son los establecidos en la Norma NTE INEN-ISO/IEC 40500, vigente [23].

Aplicando la herramienta automática T.A.W. Online sobre las tecnologías HTML y CSS de los portales web de las Unidades Educativas y Colegios se determinó los problemas, advertencias y puntos no revisados del análisis de las WCAG 2.0 con un nivel de conformidad A por cada uno de sus principios: Perceptible (P), Operable (O), Comprensible (C), Robusto (R); como se puede observar en la Tabla 6.

\begin{tabular}{|c|c|c|c|c|c|}
\hline \multirow{2}{*}{$\begin{array}{c}\text { Unidades } \\
\text { Educativas y } \\
\text { Colegios }\end{array}$} & \multirow{2}{*}{$\begin{array}{c}\text { Páginas } \\
\text { Analizada } \\
\text { s }\end{array}$} & \multicolumn{4}{|c|}{$\begin{array}{c}\text { Número de errores por } \\
\text { criterio }\end{array}$} \\
\hline & & $\mathrm{P}$ & $\mathrm{O}$ & $\mathrm{C}$ & $\mathrm{R}$ \\
\hline uesmacuenca & 5 & 249 & 134 & 26 & 256 \\
\hline ueoblatas & 5 & 194 & 123 & 51 & 3973 \\
\hline $\operatorname{sscc}$ & 6 & 84 & 66 & 30 & 2123 \\
\hline sudamericano & 7 & 108 & 72 & 33 & 7565 \\
\hline ueda & 7 & 210 & 140 & 33 & 20 \\
\hline amauta & 7 & 210 & 96 & 36 & 1297 \\
\hline
\end{tabular}




\begin{tabular}{|c|c|c|c|c|c|}
\hline arzobisposerrano & 5 & 162 & 65 & 32 & 7404 \\
\hline continental & 4 & 173 & 71 & 16 & 125 \\
\hline adistanciabg & 6 & 184 & 101 & 31 & 5229 \\
\hline manueljcalle & 3 & 46 & 29 & 14 & 130 \\
\hline herlindatoral & 4 & 249 & 101 & 25 & 1566 \\
\hline americancollege & 7 & 275 & 194 & 42 & 6464 \\
\hline mariorizzini & 7 & 213 & 179 & 50 & 1661 \\
\hline comilcue & 4 & 148 & 64 & 36 & 148 \\
\hline verbo & 7 & 175 & 87 & 36 & 1252 \\
\hline casc & 7 & 492 & 307 & 15 & 3063 \\
\hline aaschool & 7 & 238 & 116 & 21 & 548 \\
\hline catalinas & 6 & 24 & 48 & 18 & 147 \\
\hline uemo & 6 & 329 & 183 & 34 & 340 \\
\hline delasallecuenca & 7 & 28 & 56 & 21 & 189 \\
\hline laasuncion & 7 & 945 & 169 & 33 & 1496 \\
\hline santana & 7 & 858 & 146 & 56 & 103 \\
\hline madrid & 7 & 218 & 175 & 16 & 3411 \\
\hline uebi & 7 & 197 & 189 & 21 & 113 \\
\hline benignomalo & 7 & 239 & 149 & 41 & 285 \\
\hline uelac & 6 & 536 & 222 & 39 & 467 \\
\hline ueporvenir & 7 & 254 & 112 & 16 & 6020 \\
\hline uets & 7 & 293 & 94 & 38 & 4654 \\
\hline unidadborja & 7 & 417 & 485 & 28 & 5271 \\
\hline $\begin{array}{l}\text { sindicatochofere } \\
\mathrm{s}\end{array}$ & 5 & 76 & 77 & 23 & 1806 \\
\hline latinoamericano & 7 & 480 & 72 & 35 & 140 \\
\hline TOTAL: & 191 & $\begin{array}{c}830 \\
4\end{array}$ & $\begin{array}{c}412 \\
2\end{array}$ & $\begin{array}{c}94 \\
6\end{array}$ & $\begin{array}{c}6726 \\
6\end{array}$ \\
\hline \multicolumn{2}{|c|}{ Promedio errores / página } & 43,5 & 0,5 & 0,2 & 71,1 \\
\hline
\end{tabular}

Tabla 6. Análisis WCAG 2.0 páginas Unidades Educativas y Colegios.

El promedio de errores por página en la Tabla 6 , determina que hay un número significativo de errores del principio Robusto (R) 71,1, seguido por el principio Perceptible (P) 43,5. Los errores detectados son en el procesamiento, nombre, función y valor, alternativas textuales en todo el contenido no textual, información y relaciones, secuencia, características sensoriales, uso del color, contraste (mínimo), redimensionamiento del texto, texto en las Imágenes.

El Reglamento técnico ecuatoriano RTE INEN 288 "accesibilidad para el contenido web" establece en el numeral 4. REQUISITOS: inciso 4.3 En el Ecuador se exigirá que se satisfaga por completo el nivel de conformidad AA, establecido en la Norma NTE INENISO/IEC 40500, vigente $y$ en el numeral 5.

PROCEDIMIENTO PARA LA EVALUACIÓN LA CONFORMIDAD inciso 5.1 El cumplimiento de este Reglamento técnico debe ser demostrado mediante la presentación de un certificado de conformidad de primera parte, el cual debe estar colocado en el propio sitio web de acuerdo a lo que determine la autoridad competente [23].

\subsection{Análisis WCAG 2.0 en la página Home o de Inicio}

Es importante verificar el nivel de cumplimiento de las directrices del estándar WCAG 2.0 de accesibilidad web de las páginas de inicio o home de la Unidades Educativas y Colegios, teniendo en cuenta que estas páginas permite a los usuarios desplazarse dentro de los demás sitios del portal web, los resultados obtenidos del análisis se presentan en la Tabla 7por cada uno de los principios: Perceptible (P), Operable (O), Comprensible (C), Robusto (R).

\begin{tabular}{|c|c|c|c|c|}
\hline \multirow{2}{*}{$\begin{array}{c}\text { Unidades } \\
\text { Educativas y } \\
\text { Colegios }\end{array}$} & \multicolumn{4}{|c|}{ Número de errores por criterio } \\
\hline & $\mathrm{P}$ & $\mathrm{O}$ & $\mathrm{C}$ & $\mathrm{R}$ \\
\hline uesmacuenca & 71 & 43 & 5 & 23 \\
\hline ueoblatas & 65 & 55 & 12 & 979 \\
\hline $\operatorname{sscc}$ & 9 & 12 & 3 & 184 \\
\hline sudamericano & 16 & 13 & 3 & 67 \\
\hline ueda & 4 & 8 & 3 & 2 \\
\hline amauta & 39 & 21 & 5 & 178 \\
\hline arzobisposerrano & 57 & 10 & 5 & 1908 \\
\hline continental & 57 & 28 & 5 & 42 \\
\hline adistanciabg & 41 & 9 & 3 & 2 \\
\hline manueljcalle & 28 & 12 & 3 & 124 \\
\hline herlindatoral & 94 & 32 & 7 & 567 \\
\hline americancollege & 57 & 12 & 3 & 4 \\
\hline mariorizzini & 66 & 37 & 8 & 323 \\
\hline comilcue & 53 & 24 & 5 & 83 \\
\hline verbo & 33 & 11 & 5 & 181 \\
\hline casc & 6 & 8 & 3 & 2 \\
\hline aaschool & 26 & 12 & 3 & 76 \\
\hline catalinas & 4 & 8 & 3 & 12 \\
\hline uemo & 75 & 84 & 17 & 54 \\
\hline delasallecuenca & 4 & 8 & 3 & 27 \\
\hline laasuncion & 14 & 12 & 3 & 34 \\
\hline santana & 126 & 16 & 7 & 9 \\
\hline madrid & 59 & 27 & 2 & 490 \\
\hline uebi & 28 & 27 & 3 & 4 \\
\hline benignomalo & 49 & 27 & 7 & 91 \\
\hline
\end{tabular}




\begin{tabular}{|l|c|c|c|c|}
\hline uelac & 49 & 41 & 5 & 67 \\
\hline ueporvenir & 98 & 13 & 2 & 946 \\
\hline uets & 40 & 17 & 7 & 893 \\
\hline unidadborja & 133 & 120 & 2 & 771 \\
\hline sindicatochoferes & 7 & 15 & 3 & 154 \\
\hline latinoamericano & 38 & 11 & 5 & 5 \\
\hline Promedio & 47 & 25 & 5 & 268 \\
\hline Porcentaje & $\mathbf{1 3 , 5 5 \%}$ & $\mathbf{7 , 2 4 \%}$ & $\mathbf{1 , 4 1 \%}$ & $\mathbf{7 7 , 8 0 \%}$ \\
\hline
\end{tabular}

Tabla 7. Análisis WCAG 2.0 página Home Unidades Educativas y Colegios.

En la Tabla 7 se puede ver que el principio robusto (R) muestra la mayor cantidad de errores con un $77,80 \%$ lo que demuestra que hay que maximizar la compatibilidad con las aplicaciones de usuario actuales y futuras, incluyendo las ayudas técnicas.

En Reglamento técnico ecuatoriano RTE INEN 288 "accesibilidad para el contenido web" establece en el numeral 8. RÉGIMEN DE SANCIONES inciso 8.1 El propietario del sitio $w^{\mathrm{v}} \mathrm{b}^{\mathrm{v}}$ que incumpla con lo establecido en este Reglamento Técnico recibirá las sanciones previstas en la Ley No. 2007-76 del Sistema Ecuatoriano de la Calidad, Ley Orgánica de Comunicación y demás leyes vigentes [23].

\section{Resultados}

De las 191 páginas analizadas, ninguna cumple con las directrices de las WCAG 2.0 con un nivel de conformidad A, por lo tanto los portales web de las Unidades Educativas y Colegios de la ciudad de Cuenca no son accesibles.

La mayor cantidad de errores se encuentran en el contenido, debido a que las páginas web analizadas no son lo suficientemente robustas para ser interpretadas de forma fiable, por una amplia variedad de agentes de usuario, incluyendo las ayudas técnicas (procesamiento, nombre, función y valor), además se debe proporcionar alternativas textuales en todo el contenido no textual (Formularios, Imágenes, Navegación), Información y relaciones (Formularios, Estructura Semántica, Presentación), Secuencia con significado (Presentación), Características sensoriales (Presentación), Uso del color (Presentación), Contraste (Mínimo) (Presentación), Redimensionamiento del texto (Presentación), Imágenes de texto (Imágenes).

Sin embargo, en base a los resultados se determina que el $92 \%$ son advertencias que se deben revisar en el diseño y contenido de las páginas web; el $6 \%$ son problemas que se deben corregir de acuerdo a los criterios de cumplimiento (éxito) de la WCAG 2.0 y el
$2 \%$ son puntos no verificados que requieren de un análisis manual completo para su cumplimiento, como se observar en la Figura 2.

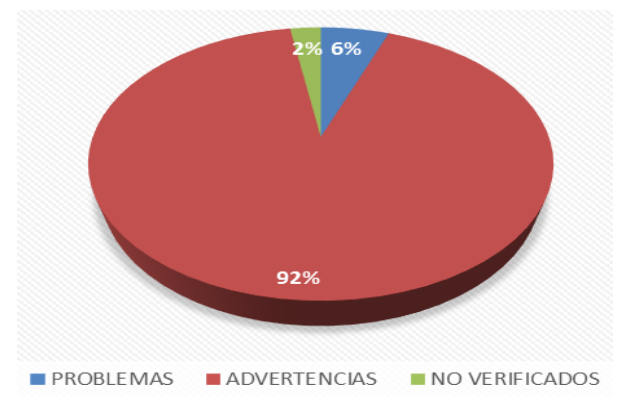

Figura 2: Resultados de problemas, advertencias y puntos no verificados.

Esto da una primera impresión de la estructura y diseño de los sitios web, considerando que los resultados son preliminares; para que los resultados sean fiables y completos se deben realizar pruebas manuales con expertos.

\section{Conclusiones}

Se requiere corregir errores en todos los portales web de las Unidades Educativas y Colegios analizados. Por el nivel y el número de errores reportados, a algunas Unidades Educativas y Colegios les resulta más factible rediseñar sus portales web, a fin de cumplir con las directrices de accesibilidad web. Es posible que algunas Unidades Educativas y Colegios puedan mejorar el cumplimiento de las pautas de accesibilidad web, con un arduo trabajo de revisión y corrección del código de sus portales web.

La adopción de la norma NTE INEN-ISO/IEC 40500 y la inclusión de estudiantes con discapacidades en la educación en el Ecuador exige que los portales web y documentos electrónicos de las Unidades Educativas y Colegios sean accesibles para el uso de cualquier persona sin importar la edad o discapacidad, arduo trabajo que los desarrolladores de software deben emprender para cumplir con las directrices de Accesibilidad web y sus niveles de conformidad, además de los cambios físicos para brindar un servicio con igualdad de oportunidades y una educación de calidad.

El desafío de la comunidad educativa es emprender proyectos de accesibilidad web para el cumplimiento de las Pautas de Accesibilidad para el Contenido Web (WCAG) 2.0 en sus sitios web con un nivel de conformidad AA como se establece en el Reglamento técnico ecuatoriano RTE INEN 288 "accesibilidad para el contenido web". 


\section{Agradecimientos}

A la Unidad Académica de Tecnologías de la Información y la Comunicación, de la Universidad Católica de Cuenca, por su apoyo para la culminación de esta investigación.

\section{Referencias}

[1] B. MUNDIAL, "Informe mundial la discapacidad," Educación, vol. 218, no. 219, p. 219, 2011.

[2] CONADIS, "Estadística personas con discapacidad.," Febrero 2016.

[3] CONADIS, "Registro nacional de discapacidades.," Abril 2015.

[4] UNICEF, Estado mundial de la infancia 2013. Mayo 2013.

[5] CONADIS, "Normas jurídicas en discapacidad ecuador.," Mayo 2014.

[6] S.N.de Planificación y Desarrollo, "Plan nacional para el buen vivir 2013-2017.," 2013.

[7] A. Zubillaga, La accesibilidad como elemento del proceso educativo: análisis del modelo de accesibilidad de la universidad complutense de Madrid para atender las necesidades educativas de los estudiantes con discapacidad. PhD tesis, Universidad Complutense de Madrid., 2010.

[8] W. P. Docs, "Fundamentos de la accesibilidad web.," [En línea]. Available: https://docs.webplatform.org/wiki/concepts/acces sibility/es [Último acceso: 03 Agosto 2016].

[9] J.de Castilla y León, “Accesibilidad para todos., "Mayo 2011.

[10] A. Pascual Almenara et al., "Accesibilidad en entornos web interactivos: superación de las barreras digitales," Abril 2015.

[11]CONADIS, "Accesibilidad web en ecuador.," Enero 2014.[En línea]. Available: http://accesibilidadwebecuador.blogspot.com/201 5/02/adopcion-de-la-norma-isoiec-40500.html [Último acceso: 03 Agosto 2016].

iUna barrera de accesibilidad es una condición que dificulta a una persona con discapacidad el acceso a un elemento o la realización de una tarea. Y se produce cuando el usuario no puede acceder o interaccionar con una información específica del contenido [10].

${ }^{\text {ii }} \mathrm{Se}$ da el nombre de unidades educativas y colegios porque algunas instituciones ofertan bachillerato y educación básica general y el portal web para los dos casos es el mismo.

iii Contenido web. Se refiere a los elementos textual, visual o sonoro obtenido mediante una dirección de
[12] S.N.de la Administración Pública, "Boletín de prensa accesibilidad web en ecuador.," Mayo 2014.

[13] W3C, "Guía breve de accesibilidad web." [En línea]. Available: http://w3c.es/Divulgacion/GuiasBreves/Accesibil idad [Último acceso: 03 Agosto 2016].

[14] S. L. Henry, "Introducción a la accesibilidad web.," Septiembre 2005.

[15] ONCE-CIDAT, Guía de referencia: Accesibilidad de páginas Web, 2013.

[16] S. L. Mora, Accesibilidad Web. Universidad de Alicante, España. [En línea]. Available: http://accesibilidadweb.dlsi.ua.es/[Último acceso: 03Agosto 2016].

[17]C. de Empresarios de Andalucía., “¿qué es la accesibilidad web?," España, 2010.

[18] S. L. Mora, Pautas de accesibilidad al contenido web 2.0 (WCAG 2.0). Universidad de Alicante, España.[En línea]. Available: http://accesibilidadweb.dlsi.ua.es/?menu=pautas2.0 [Último acceso: 03Agosto 2016].

[19] S. L. Mora, Niveles de adecuación de WCAG 2.0. Universidad de Alicante, España. [En línea]. Available:

http://accesibilidadweb.dlsi.ua.es/?menu=niveles2.0 [Último acceso: 03Agosto 2016].

[20]C. de Empresarios de Andalucía, "Accesibilidad web. niveles wcag 2.0," 2010.

[21] R. Navarrete and S. Luján, "Accesibilidad web en las universidades del ecuador. análisis preliminar," Revista Politécnica, vol. 33, no. 1, 2014.

[22] J. J. C. Valdivieso et al., Herramientas Automáticas para la Accesibilidad Web: Una Aplicación en Campus Universitarios de Excelencia 2010. Lulu. com.

[23]A. E. C. Vásconez, "Reglamento técnico ecuatoriano RTE INEN 288 "accesibilidad para el contenido web"," Enero 2016.

[24] D. Ecuador, “Tipos de dominios,” 2016.[En línea]. Available: https://nic.ec/info/dominios.htm [Último acceso: 03Agosto 2016].

Internet. El contenido web puede incluir, entre otras cosas: texto, imágenes, sonidos,

videos y animaciones [23].

iv Sitio web. Es un espacio virtual en Internet, se trata de un conjunto de páginas web relacionadas a un mismo dominio o subdominio [23].

${ }^{v}$ Propietario del sitio web. Es el representante legal de la institución que posee un sitio web publicado en internet [21]. 